


\title{
O PROGRAMA TV ESCOLA: DESAFIOS À INTRODUÇÃO DE NOVAS TECNOLOGIAS
}

\author{
SÔNIA M. DRAIBE \\ Professora do Instituto de Economia e pesquisadora do NEPP - UNICAMP \\ JOSÉ ROBERTO RUS PEREZ \\ Professor da Faculdade de Educação e pesquisador do NEPP - UNICAMP
}

\begin{abstract}
RESUMO
Este trabalho examina o processo de implementação dos programas federais Kit Tecnológico e TV Escola, expondo de modo resumido os principais resultados de pesquisa recente que avaliou, em âmbito nacional, o seu processo de implementação.

O processo recente de introdução de sistemas de educação a distância nas redes públicas municipais e estaduais brasileiras oferecem uma excelente oportunidade para o estudo dos fatores que obstaculizam o seu pleno funcionamento. E, do ponto de vista contrário, identificar os fatores que, nas condiçóes concretas de nossas escolas, têm facilitado a utilização de filmes didáticos nas práticas escolares e em que medida esses meios didáticos aparecem como vantajosos aos agentes que, potencialmente, deles se utilizarão ou se beneficiarão e, porisso mesmo, podem apoiar e facilitar sua introdução.

EDUCAÇÃOADISTÂNCIA_POLITIICAEDUCACIONAL — IMPLEMENTAÇÃODEPROGRAMASEDUCACIONAIS-AVALIAÇÃODEPOLITICAS
\end{abstract}

\begin{abstract}
THEPROGRAM TVESCOLA: PERSPECTIVESAND CHALLENGESIN THEINTRODUCTION OFNEW TECHNOLOGIES INTO THESCHOOL ENVIRONMENT. This work examines the process of implementing the federal programs Kit Tecnológico [Technology Kit] and TV Escola [TVSchool], explaining in a succinct way the main results of a recent study to evaluate the implementation process on the national level.

The recent introduction of educational extension systems into Brazilian public municipal and state networks offers an excellent opportunity to study factors that are obstacles to their full functioning, and to identify those factors that in the real situation of our schools have facilitated the use of didactic films and how they appear advantageous to those who potentially use or benefit from them - and for this same reason can help with and facilitate their introduction.
\end{abstract}


A introdução, com fins didáticos, de novas tecnologias no ambiente escolar, constitui processo complexo, que, em geral, enfrenta obstáculos de diferentes ordens, entre eles, as resistências originadas na cultura interna da escola e nas rotinas tradicionais de trabalho tanto do professor quanto do pessoal técnico-pedagógico. Romper ou mesmo flexibilizar hábitos e práticas já conhecidas e dominadas, introduzindo mecanismos e sistemas que, de início, parecem "escapar ao controle" dos sujeitos, e que podem ser vistos como ameaças à sobrevivência de sua própria função - eis o quadro de fundo que, freqüentemente, opera como fator de impedimento ou atraso dos processos de utilização de equipamentos de mídia e informática na sala de aula e na capacitação docente.

No plano institucional e da organização escolar, também são inúmeros os fatores que tendem a operar como obstáculos à introdução e rotinização de tais instrumentos e meios didáticos. De fato, a economia da escola e sua tradicional divisão interna de trabalho, ao mesmo tempo que tende a supor uma forte autonomia do professor dentro da "sua" classe, delega também ao diretor, a supervisores e coordenadores pedagógicos - localizados na escola ou nas instâncias intermediárias das redes de ensino - a responsabilidade pela introdução e "calibragem" de inovações como as referidas. Ora, pode-se supor que, se tais agentes não se mobilizam pela introdução dessas inovações no planejamento escolar e nas atividades de orientação e capacitação docente, dificilmente poderão elas integrar-se plenamente às rotinas de trabalho. Resta, como alternativa, tão somente a iniciativa do professor - sempre e quando aqueles fatores psicossociais inicialmente referidos não o inibam totalmente.

$\bigcirc$ processo recente de introdução de sistemas de educação a distância nas redes públicas municipais e estaduais brasileiras oferecem uma excelente oportunidade para o estudo dessas questões. No nosso caso, com que especificidade aqueles fatores que constituem obstáculos operam? E, do ponto de vista contrário, que fatores, nas condições concretas de nossas escolas, têm facilitado a utilização de filmes didáticos nas práticas escolares? Em que medida esses meios didáticos aparecem como vantajosos aos agentes que, potencialmente, deles se utilizarão ou se beneficiarão - e, por isso mesmo, podem apoiar e facilitar sua introdução?

Este trabalho examina, sob essas perspectivas, o processo de implementação dos programas federais Kit Tecnológico e TV Escola, expondo de modo resumido, os principais resultados de pesquisa recente que avaliou, em âmbito nacional, o seu processo de implementação.'

É interessante considerar o Programa TV Escola tendo por quadro de fundo a situação do sistema de ensino no país. Assistiu-se, no Brasil, a um grande esforço da sociedade para

1. A pesquisa Avaliação da Descentralização dos Programas Federais de Apoio ao Ensino Fundamenta/foi realizada em 1997 mediante convênio entre o Núcleo de Estudos de Políticas Públicas - NEPP, da UNICAMP e o INEP/ MEC, tendo avaliado, além do Kit e da TV Escola, os programas da Merenda Escolar (Programa Nacional de Alimentação Escolar - PNAE) e o Dinheiro na Escola (Programa de Manutenção e Desenvolvimento do Ensino - PMDE). Em 1998, para fins de comparação, repetiu-se a avaliação da TV Escola, pelo projeto Avaliação Comparativa da TV Escola. Os autores participaram dos referidos projetos como coordenadores científicos de uma equipe que envolveu aproximadamente cinqüenta consultores, pesquisadores e estagiários. 
ampliar os níveis de escolarização da população, principalmente no ensino fundamental. Inúmeros programas foram implementados tanto pelo governo federal quanto pelos estados e municípios. Contudo, persistem críticas contundentes sobre a qualidade do ensino público. Como mostram ainda as taxas de efetividade, o quadro mais geral do sistema educacional brasileiro é crítico, em particular pelos altos índices de reprovação que contribuem para afastar o aluno da escola, comprometendo o acesso e alavancando a evasão.

Para explicar esse fracasso escolar são evocados inúmeros argumentos. Entre os que interessam mais de perto a este estudo, destacam-se o baixo grau de qualificação do corpo docente e a precariedade de recursos didáticos em sala de aula.

A capacitação de professores em serviço constitui, sem dúvida, um dos pré-requisitos fundamentais para a introdução de inovações educacionais na rede de ensino. Mas, se por um lado, alguns estudos apontam para a importância da capacitação, considerada como uma variável que tem um impacto diferencial sobre o rendimento de aprendizagem dos alunos, por outro, sabe-se também da imensa dificuldade em realizar cursos de capacitação eficientes e que atinjam a grande maioria dos profissionais. As ações nessa área têm sido pontuais; diferenciam-se muito entre as redes, entre os estados e os municípios; e apresentam sempre baixa cobertura, atingindo pequeno número de professores.

Quanto aos recursos didáticos, entendidos como a tecnologia educacional à disposição das escolas, a situação também é muita complexa. A transmissão de conhecimento, na escola pública brasileira, está apoiada basicamente na atuação do professor. A incorporação e o emprego de novos meios de transmissão é lenta e precisa enfrentar inúmeros obstáculos. Um exemplo típico foi a incorporação do livro didático, considerado atualmente como o instrumento mais importante de que dispõe o professor na sua rotina escolar e no processo de ensino-aprendizagem. Reconhecendo tal importância, o governo federal mantém, há décadas, programas de distribuição de livros às escolas de ensino fundamental, secundado pelo esforço de editoras na divulgação e popularização desse material didático, principalmente junto aos professores.

Nos últimos anos, assistiu-se ao crescente desenvolvimento dos meios de comunicação de massas, dentre os quais destacam-se o rádio, a televisão e o jornal, e também dos recursos multimídia através da informática. Esses novos produtos, inicialmente muito caros, foram maciçamente incorporados ao cotidiano das pessoas apenas na década de oitenta. ${ }^{2}$ Mas, seguramente, possibilitaram uma renovação da tecnologia educacional, já que, ao se contar com esses novos recursos, foram ampliadas as formas de enfrentamento dos problemas educacionais. Apesar da existência de uma enorme controvérsia em relação a essa nova potencialidade, cada vez mais aceita-se que tanto o computador quanto a televisão podem melhorar e enriquecer a experiência do aprendizado, auxiliando o professor em sua rotina escolar.

2. Segundo dados do Censo de 1991 , cerca de $80 \%$ dos domicílios urbanos possuem um aparelho de televisão. 
A utilização de tecnologias educacionais nas escolas públicas brasileiras vem sendo discutida há muitos anos. Inúmeras experiências pontuais foram realizadas pelo governo federal e também por algumas unidades da federação. Elas, basicamente, consistiam no uso da televisão e rádios educativos. Dentre os projetos de teleducação de iniciativa federal, destacam-se: Saci, Minerva, Telecursos de $1{ }^{\circ}$ e $2^{\circ}$ Graus. Na área de capacitação de professores algumas iniciativas também aconteceram, como o Programa Um Salto para o Futuro, produzido, desde 1991, pela Fundação Roquette Pinto. A partir de 1993, com as discussões em torno do Plano Decenal para a Educação, ganha força a idéia de valorização do magistério e da utilização do ensino a distância. ${ }^{3}$

Nesse contexto, em 1995, o MEC formulou e passou a implementar uma política educacional pautada pelo objetivo de valorização do magistério. Dentre as várias ações propostas com esse objetivo, destaca-se a capacitação de professores por meio da educação a distância. Surgiram assim o Programa TV Escola e o Programa de Apoio Tecnológico.

O Programa de Apoio Tecnológico - PAT, mais conhecido como Kit Tecnológico, foi formulado 4 nos primeiros meses de 1995, tendo por meta fornecer a todas as escolas públicas de ensino fundamental um kit composto por uma televisão, um videocassete, uma antena parabólica e uma caixa de fitas VHS. ${ }^{5}$ Segundo as definições do desenho original, o universo a ser atendido é constituído pelo conjunto de escolas com mais de cem alunos, hoje estimado em 42 mil escolas em todo o país.

Tendo metas universalizantes ${ }^{6}$ e caráter progressivo, ${ }^{7}$ o programa obedeceu a uma lógica gradual de implementação, objetivando alcançar o universo de escolas no espaço de

3. Também a Lei de Diretrizes e Bases da Educação Nacional, lei 9.394 de 1996, estabelece que o Poder Público "incentivará o desenvolvimento e a veiculação de programas de ensino a distância em todos os níveis e modalidades de ensino, e de educação continuada" (art. 80).

4. A Resolução n. 15, do Fundo Nacional para o Desenvolvimento da Educação - FNDE, de junho de 1995 , instituiu o Programa de Apoio Tecnológico para as escolas das redes estadual e municipal do Ensino Fundamental.

5. Ficou estabelecido que o aparelho de TV deveria ser em cores, de pelo menos 20 polegadas, bivolt e com controle remoto; o videocassete deveria ser de quatro cabeças, com controle remoto, bivolt e sistemas NTSC/ PALM; o conjunto de recepção de satélite seria composto por uma antena parabólica com diâmetro variando entre 2,7 e 2,85 metros, um amplificador de baixo ruído, LNB, de 25 graus, um receptor de satélite e um servo-motor; e a caixa de fitas VHS deveria conter, no mínimo, dez unidades.

6. O PAT tinha como meta atender todas as escolas estaduais e municipais com mais de 250 alunos no ensino fundamental. No caso de o município não contar com escolas desse porte, deveria ser escolhida a escola com maior número de alunos. Dois meses depois de implementado o programa, o limite mínimo por escola foi alterado, sendo reduzido para cem alunos.

7. Pela Resolução FNDE n²6, de 19/3/96, foi criado o Plano de Complementação e Expansão do Programa de Apoio Tecnológico à Escola, que instituiu o repasse de mil reais para a aquisição de um equipamento adicional (televisão, videocassete e duas caixas com dez fitas VHS cada) para as escolas localizadas na Região Norte, Nordeste e Centro-Oeste, exceto o Distrito Federal e os municípios sem escolas (municipal ou estadual) com mais de cem alunos. Este plano visava atingir as escolas que não tinham sido contempladas em 1995, incluindo também escolas de educação especial e indígena. $\bigcirc$ plano ainda estabeleceu que as secretarias de educação 
aproximadamente dois anos. ${ }^{8}$ Com relação à execução, optou-se pela compra descentralizada do equipamento por parte das prefeituras municipais (para escolas da rede municipal) e secretarias estaduais de educação (para escolas desta rede). ${ }^{9}$

O Programa de Apoio Tecnológico constituiu a base material de outro programa iniciado pelo MEC no mesmo período - o Programa TV Escola, um complexo de ações televisivas destinadas à capacitação docente e à ampliação do acesso dos alunos às novas informações. O referido programa organiza-se tendo como perspectiva um canal de televisão, exclusivamente educativo, cujos sinais são gerados pela Fundação Roquette Pinto para o satélite de comunicação Brasilsat- I e transmitidos para todo o país em circuito fechado.

A sua operacionalização envolve, no âmbito federal, a Secretaria de Educação a Distância - SEED, ${ }^{10}$ cujas principais funções abarcam a produção e execução dos programas; a pesquisa, compra e dublagem de vídeos e programas; a realização da articulação com as secretarias estaduais e prefeituras; a produção e disseminação de material impresso. No nível estadual, as secretarias estaduais de educação são responsáveis pela elaboração de orientação para as escolas e pela capacitação dos recursos humanos para a utilização de programas de ensino a distância. Finalmente, na outra ponta do programa, estão as unidades escolares, que devem gravar os programas transmitidos, montar a videoteca, designar um profissional para coordenar as atividades, criar condições para os professores assistirem aos programas e divulgar o material impresso.

É de se notar que, operando um programa emitido para redes sobre as quais não tem, em princípio, ingerência nem poder de gestão — uma vez que são de responsabilidades de estados e municípios, entidades federativas dotadas de acentuado grau de autonomia, como se sabe — o MEC apostou aqui em um modelo fortemente descentralizado e autônomo, uma vez que, em última instância, delegou à unidade escolar o total arbítrio para o uso da TV Escola. Inegavelmente vantajoso em muitos aspectos, o modelo, como veremos, esbarrou, entretanto, em dificuldades organizacionais importantes.

dos estados e do Distrito Federal e as prefeituras municipais deveriam dotar de energia elétrica as respectivasescolas estaduais e municipais com mais de cem alunos no ensino fundamental que, eventualmente, não fossem servidas de energia, de modo a possibilitar a instalação dos equipamentos.

8. As metas foram definidas para 1996 e 1997, devendo ser contempladas, no segundo ano, as escolas não contempladas no primeiro ano, mediante projetos das prefeituras municipais. Em março de 1996, o prazo de cumprimento de metas da primeira etapa foi prorrogado até 31 de dezembro de 1996.

9. Utilizando-se da cota federal do salário-educação, o FNDE repassou recursos financeiros para as secretarias estaduais de educação e prefeituras comprarem os equipamentos para suas respectivas redes. Os repasses foram efetuados mediante a celebração de um convênio, sendo o seu valor de R\$ 1.500,00 por escola.

10. Criada no início do ano de 1996 e localizada no MEC, a secretaria é responsável por implantar a política do governo federal de ensino a distância e de informatização das escolas públicas. 
A pesquisa Avaliação da Descentralização dos Programas Federais de Apoio ao Ensino Fundamental - Avaliação da TV Escola - tipicamente uma avaliação de processo, teve por objetivo avaliar a implementação do Programa de Apoio Tecnológico (Kit Tecnológico) e do Programa TV Escola nas redes públicas municipais e estaduais de ensino fundamental, bem como identificar os fatores institucionais e organizacionais que operam como facilitadores ou como obstáculos à sua implantação e funcionamento. Buscou ainda estimar os graus de satisfação dos principais agentes e beneficiários com o Programa TV Escola. Para a consecução dos seus objetivos, a investigação utilizou métodos quantitativos e qualitativos, apoiandose em surveys nacionais e estudos de caso. " As informações aqui expostas correspondem às coletadas dos dados da amostra nacional.

Quatro constatações principais podem ser extraídas do quadro de implementação e funcionamento do Programa TV Escola. A primeira, refere-se à presença do Programa em aproximadamente dois terços das escolas públicas brasileiras, atingindo cerca de $73 \%$ dos alunos (21,9 milhões) e 70\% dos docentes (840 mil) do ensino fundamental público. Em pouco menos da metade das escolas, a capacitação docente pela programação emitida, ocorre com periodicidade semanal ou, no máximo, mensal. Em segundo lugar, é possível inferir, com base nos indicadores de eficácia, o avanço do processo de institucionalização do Programa, sugerindo um crescente "amoldamento" das atividades da TV Escola às estruturas e rotinas pedagógicas escolares. Os indicadores de desempenho também mostram diferenças entre grupos de escolas, sendo as desigualdades mais acentuadas entre regiões - em detrimento das escolas das duas regiões mais pobres - e entre escolas municipais e estaduais, em detrimento das primeiras. Mas as melhoras verificadas entre 1997 e 1998 tenderam a reduzir essas diferenças, reforçando os impactos redistributivos da TV Escola. Ao final, praticamente, todos os indicadores revelam melhoras entre 1997 e 1998, registrando êxitos do processo de implementação em superar as dificuldades e obstáculos que enfrentou no seu início, há dois anos.

Os principais indicadores e evidências estão, a seguir, registrados.

1 I. O Módulo I da pesquisa realizou dois surveys nacionais com diretores escolares, nos quais foram utilizados questionários aplicados a uma amostra estratificada de 5.084 diretores de escolas públicas municipais e estaduais, tendo se obtido taxas de retorno de 62,8\% em 1997 (3.193 diretores) e de 49,5\% em 1998 (2.519 diretores). O Módulo II, realizado em 1997, foi constituído de estudos de casos desenvolvidos em 34 municípios (capitais e municípios pequenos, médios e grandes) de oito unidades da federação, por aproximadamente trezentas entrevistas com os seguintes tipos de atores relevantes: delegados de ensino; secretários estaduais de educação; técnicos estaduais responsáveis pelos programas; diretores de escolas estaduais; prefeitos municipais das oito capitais e dos 26 municípios do interior; secretários municipais de educação; técnicos municipais; diretores de escolas municipais; técnicos das escolas; professores; alunos; pais de alunos; membros dos colegiados das escolas; membros dos conselhos municipais de educação. No total, foram realizadas cerca de 300 entrevistas com os múltiplos agentes, aplicados 1500 questionários a alunos de $4^{\text {as }}$ séries aleatoriamente agrupados nas suas respectivas escolas; cerca de trezentos questionários aplicados a professores de 1 as a $4^{\text {as }}$ séries, com os quais também realizaram-se cerca de 64 grupos focais acerca do Programa TV Escola. 
Indicadores de resultados: cobertura e destinação do programa

Em 1997, três entre quatro escolas urbanas com mais de cem alunos tinham recebido o kite onde este já estava em funcionamento, pouco menos de 2/3 gravavam os filmes exibidos. Em 1998, a cobertura do kit atingiu 90\% das escolas e cresceu em 5\% o número de escolas que gravavam programas. Este crescimento foi mais significativo nas escolas do Nordeste e, entre estas, nas escolas municipais (23\% e 25\% respectivamente), seguidas das escolas da Região Norte (20\%). Portanto, a expansão ocorreu, sobretudo nas regiões e municipalidades que apresentavam as menores taxas de cobertura no ano anterior, indicando êxito das estratégias de implementação que trataram de melhorar a eqüidade do Programa.

QUADRO I

KIT TECNOLÓGICO/TV ESCOLA. INDICADORES DE DESEMPENHO: COBERTURA E FUNCIONAMENTO

Brasil e Regiões, 1997 - 1998

Percentual de escolas urbanas

\begin{tabular}{|c|c|c|c|c|c|c|c|c|c|c|c|c|c|c|c|c|c|c|}
\hline \multirow{3}{*}{ Cobertura } & \multirow{2}{*}{\multicolumn{3}{|c|}{ Brasil }} & \multicolumn{15}{|c|}{ Regiões } \\
\hline & & & & \multicolumn{3}{|c|}{ Norte } & \multicolumn{3}{|c|}{ Nordeste } & \multicolumn{3}{|c|}{ COeste } & \multicolumn{3}{|c|}{ Sudeste } & \multicolumn{3}{|c|}{ Sul } \\
\hline & 97 & 98 & $\boldsymbol{\Delta}$ & 97 & 98 & $\boldsymbol{\Delta}$ & 97 & 98 & $\mathbf{A}$ & 97 & 98 & $\mathbf{\Delta}$ & 97 & 98 & $\mathbf{\Delta}$ & 97 & 98 & $\boldsymbol{\Delta}$ \\
\hline Escolas que receberam o kit & 78 & 90 & 16 & 73 & 88 & 20 & 68 & 84 & 24 & 87 & 95 & 9 & 82 & 93 & 13 & 84 & 95 & 14 \\
\hline . Com kit instalado & 96 & 92 & -4 & 95 & 88 & -7 & 93 & 91 & -2 & 96 & 89 & -7 & 98 & 94 & -4 & 97 & 94 & -3 \\
\hline Com kit funcionando & 83 & 92 & 10 & 79 & 91 & 15 & 78 & 84 & 7 & 80 & 95 & 18 & 89 & 98 & 9 & 79 & 89 & 12 \\
\hline - Realizam gravações & 61 & 64 & 5 & 48 & 58 & 19 & 46 & 49 & 6 & 63 & 69 & 9 & 73 & 74 & 2 & 64 & 65 & 1 \\
\hline Possuem + 100 filmes & 37 & 39 & 6 & 24 & 30 & 27 & 19 & 19 & 0 & 26 & 39 & 54 & 48 & 44 & -8 & 38 & 53 & 40 \\
\hline
\end{tabular}

Fonte: NEPP/UNICAMP, 1998

* = Taxa de crescimento

Verifica-se, no quadro acima, a quase universalização da distribuição do kit (a menor taxa de cobertura é a da região Nordeste, com 84\%), o crescimento de $16 \%$ entre 1997 e 1998 e, mais importante ainda, a redução das disparidades de cobertura, uma vez que foram as duas regiões anteriormente menos contempladas, o Nordeste e o Norte, as que apresentam as mais altas taxas de crescimento - $24 \%$ e $20 \%$ respectivamente.

equipamento está instalado e em bom estado de funcionamento igualmente em todas as regiões. ${ }^{12}$ Bem menor - embora alcançando entre metade e 2/3 das escolas mostra-se a participação daquelas que gravam os filmes do programa. Essas cresceram cerca

12. Registra-se queda, entre 1997 e 1998, no indicador "instalados", o que provavelmente devido à demora de instalação nas escolas que receberam o kit em 1997, principalmente as escolas municipais do Norte e do Nordeste. 
de $5 \%$ entre um ano e outro, mas cresceram sobretudo as escolas municipais do Sudeste (49\%), as municipais e estaduais do Norte (20\% e 16\%), as estaduais do Centro-Oeste (16\%) e as municipais do Nordeste (1 I,7\%).

Dois outros indicadores retratam também o desempenho do programa: a destinação e a periodicidade do uso dos filmes reproduzidos pelo público-alvo (alunos ou professores) e a intensidade do seu uso. Veja-se o Quadro 2:

QUADRO 2

TV ESCOLA. PÚBLICO- ALVO E PERIODICIDADE

DA UTILIZAÇÃO DOS PROGRAMAS

Brasil e Regiões, 1997 - 1998

Percentual de escolas urbanas

\begin{tabular}{|c|c|c|c|c|c|c|c|c|c|c|c|c|c|c|c|c|c|c|}
\hline \multirow[t]{2}{*}{$\begin{array}{l}\text { Público-alvo/ } \\
\text { periodicidade }\end{array}$} & \multicolumn{3}{|c|}{ Brasil } & \multicolumn{3}{|c|}{ Norte } & \multicolumn{3}{|c|}{ Nordeste } & \multicolumn{3}{|c|}{ C.Oeste } & \multicolumn{3}{|c|}{ Sudeste } & \multicolumn{3}{|l|}{ Sul } \\
\hline & 97 & 98 & $\overline{\mathbf{A}}$ & 97 & 98 & $\boldsymbol{\Delta}$ & 97 & 98 & $\overline{\mathbf{\Delta}}$ & 97 & 98 & $\overline{\boldsymbol{\Delta}}$ & 97 & 98 & $\overline{\mathbf{\Delta}}$ & 97 & 98 & $\overline{\mathbf{A}}$ \\
\hline Com docentes & 59 & 61 & 3 & 60 & 54 & -4 & 54 & 48 & -11 & 62 & 64 & 3 & 64 & 73 & 14 & 56 & 56 & 0 \\
\hline . Utilização semanal & 22 & 25 & 13 & 25 & 25 & 0 & 26 & 20 & -25 & 26 & 26 & 0 & 21 & 35 & 64 & 13 & 11 & -13 \\
\hline Comalunos & 66 & 68 & 3 & 65 & 69 & 5 & 57 & 55 & -3 & 74 & 74 & 0 & 71 & 74 & 4 & 65 & 70 & 9 \\
\hline . Utilização semanal & 34 & 35 & 4 & 35 & 41 & 16 & 37 & 27 & -26 & 34 & 39 & 4 & 32 & 40 & 20 & 31 & 36 & 16 \\
\hline
\end{tabular}

Fonte: NEPP/UNICAMP, 1998

" = Taxa de crescimento

Embora concebido como um programa prioritariamente destinado à capacitação docente, a TV Escola é mais usada com alunos do ensino básico. Contudo, entre 1997 e 1998, a sua utilização com docentes cresceu proporcionalmente mais. É positivamente surpreendente que entre $30 \%$ e $40 \%$ das escolas indiquem periodicidade semanal de uso, principalmente com alunos. Finalmente, merece destaque o fato de que, embora as escolas das regiões mais desenvolvidas sejam as que mais assinalam o uso da TV Escola com docentes e com alunos, é nas regiões mais carentes que o uso semanal se faz de modo mais intenso. ${ }^{13}$

Os dois grupos de indicadores de desempenho comportam-se de maneira bastante desigual, quando se comparam escolas municipais e estaduais, de um lado, e escolas pequenas, médias e grandes, de outro. Em geral, as escolas municipais e as escolas pequenas registram piores resultados, como pode se ver no Quadro 3.

As grandes diferenças entre escolas municipais e estaduais tenderam a se reduzir entre 1997 e 1998, dadas as maiores taxas de crescimento registradas entre as primeiras. Note-se que, diferentemente dos outros indicadores, as escolas localizadas nos municípios pequenos tendem a gravar mais que as localizadas nos médios e grandes.

13. Em 1997, verificou-se ainda que, em 17\% das escolas, nenhum professor usava o programa, porém em I I\%, todos os professores utilizam os filmes com os alunos; em $28 \%$, a metade ou mais dos professores faz uso do equipamento e filmes. 
QUADRO 3

TV ESCOLA. INDICADORES DE DESEMPENHO

SEGUNDO GRUPOS DE ESCOLAS

Brasil, 1997/1998

Percentual de escolas urbanas

\begin{tabular}{|c|c|c|c|c|c|c|c|c|c|c|c|c|c|c|c|}
\hline \multirow{3}{*}{ Categorias de Escolas } & \multicolumn{15}{|c|}{ Formas de recebimento dos benefícios } \\
\hline & \multicolumn{3}{|c|}{ Possuem Kit } & \multicolumn{3}{|c|}{ Instalado } & \multicolumn{3}{|c|}{ Funcionando } & \multicolumn{3}{|c|}{ Gravam } & \multicolumn{3}{|c|}{$\begin{array}{c}\begin{array}{c}\text { Possuem }+100 \\
\text { filmes }\end{array} \\
\end{array}$} \\
\hline & 97 & 98 & $\mathbf{\Delta}$ & 97 & 98 & $\boldsymbol{\Delta}$ & 97 & 98 & $\mathbf{\Delta}$ & 97 & 98 & $\boldsymbol{\Delta}$ & 97 & 98 & $\boldsymbol{\Delta}$ \\
\hline Escolas Estaduais & 87 & 98 & 13 & 96 & 93 & -3 & 85 & 93 & 9 & 66 & 67 & 2 & 38 & 42 & 10 \\
\hline Escolas Municipais & 60 & 74 & 25 & 94 & 88 & -6 & 78 & 89 & 14 & 46 & 53 & 15 & 29 & 25 & -12 \\
\hline Escolas grandes & 84 & 96 & 14 & 97 & 92 & -6 & 83 & 95 & 15 & 66 & 73 & 10 & 44 & 41 & -7 \\
\hline Escolas médias & 76 & 88 & 16 & 96 & 93 & -2 & 84 & 89 & 5 & 58 & 58 & -1 & 22 & 37 & 68 \\
\hline Escolas pequenas & 60 & 76 & 27 & 92 & 88 & -5 & 80 & 91 & 13 & 46 & 43 & -6 & 13 & 26 & 101 \\
\hline Munic. Grandes & 76 & 90 & 19 & 96 & 93 & -3 & 77 & 95 & 23 & 55 & 61 & 11 & 24 & 29 & 21 \\
\hline Munic. Médios & 76 & 88 & 15 & 96 & 90 & -6 & 87 & 76 & -13 & 60 & 64 & 5 & 32 & 48 & 52 \\
\hline Munic. Pequenos & 81 & 90 & 11 & 96 & 91 & -6 & 80 & 93 & 17 & 70 & 68 & -4 & 43 & 47 & 8 \\
\hline Total das escolas & 78 & 90 & 16 & 96 & 92 & -4 & 83 & 92 & 10 & 61 & 64 & 4 & 36 & 38 & 5 \\
\hline
\end{tabular}

Fonte: NEPP/UNICAMP, 1998

* = Taxa de crescimento

Indicadores de eficácia

Características e qualidades do processo de implementação do programa explicam seguramente grande parte do seu desempenho. Os indicadores apresentados no Quadro 4 retratam o modo como o Programa TV Escola vem sendo operado nas escolas públicas de ensino fundamental. Inicialmente verifica-se uma tendência de ampliação da autonomia da escola — principalmente da estadual — em relação à manutenção do equipamento. Verificase que, em 1998, em mais da metade (56\%), a própria escola providenciara o seu conserto. Em 1997, esse percentual era de 47\%.

As informações revelam ainda outros aspectos da eficácia do programa, que convém explorar. Ainda em relação à capacitação, o programa também investiu no envio de material impresso às escolas. Assim, a Revista da TV Escola - instrumento de informação e capacitação rotineira do programa - chegava a mais de 3/4 das escolas (70\%) em 1997, percentual que, em 1998, se elevou em 13\%.

É possível, por outro lado, estimar o grau de institucionalização do programa, através do nível da sua inserção nas atividades eminentemente pedagógicas da escola. Pois bem, os dados mostram um envolvimento crescente do coordenador pedagógico com a TV Escola, selecionando os filmes em metade das escolas e gravando-os em aproximadamente I/4 delas. 


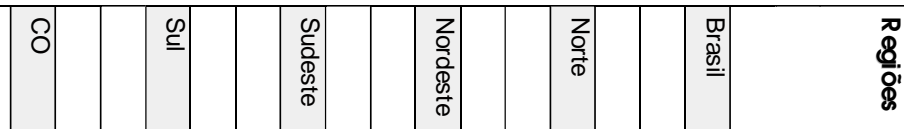

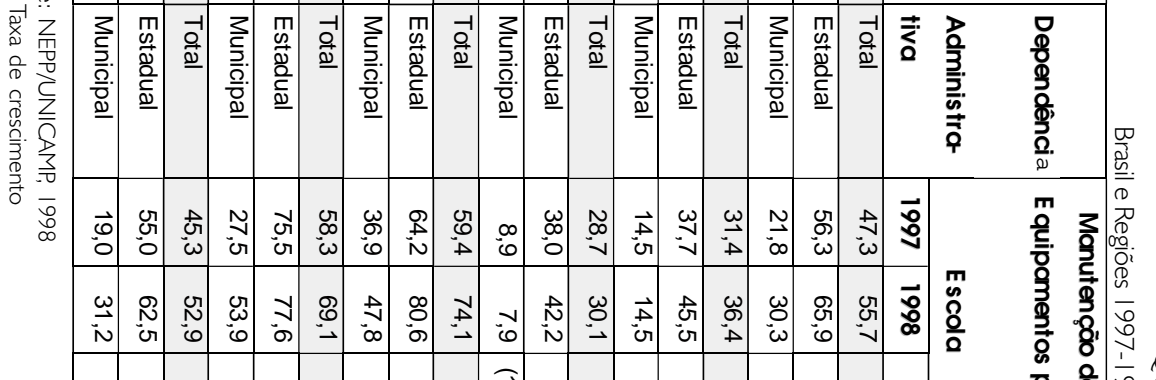

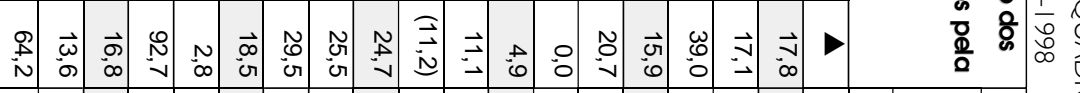

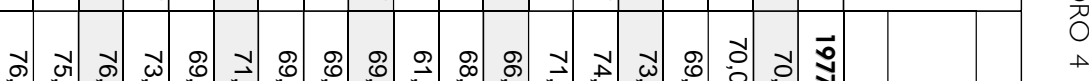

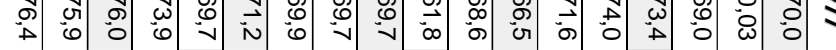

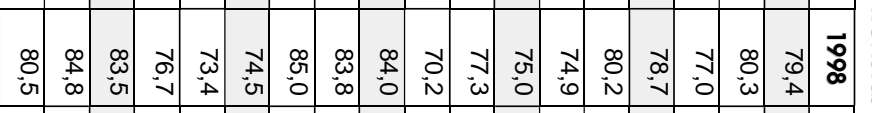

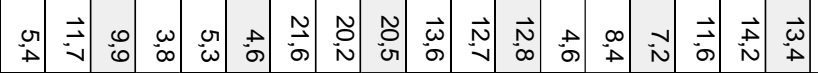

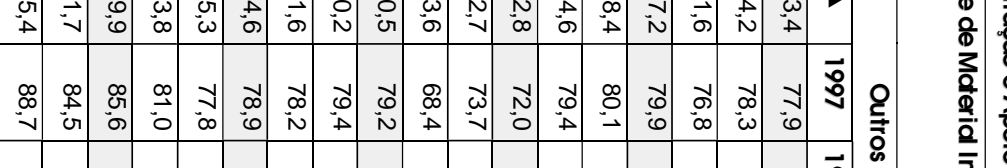

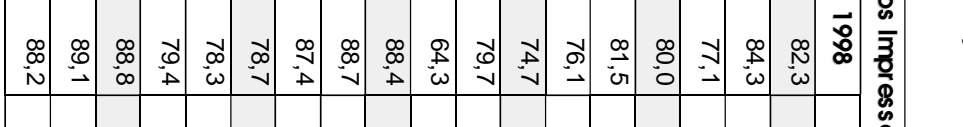



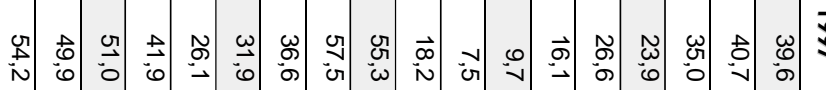

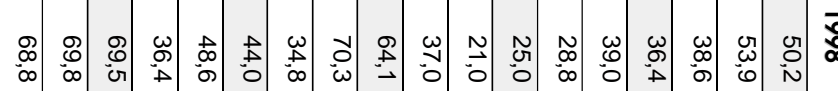

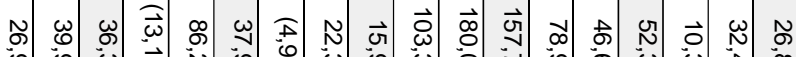

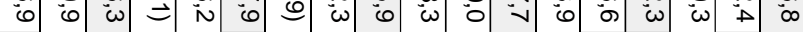

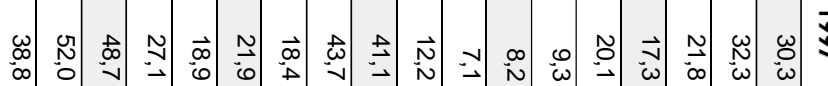

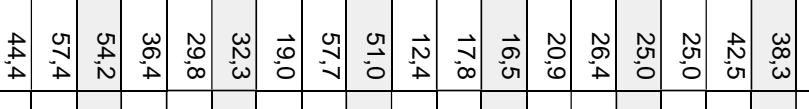

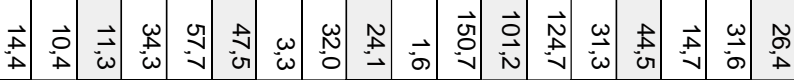

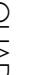


Visando conhecer mais profundamente como se dá a utilização da programação da TV Escola e mesmo do uso do kit, inquiriu-se os diretores sobre os principais tipos de programas (programação da TV Escola, programas musicais e shows, programas esportivos, documentários e filmes alugados) utilizados em atividades pedagógicas com os alunos. A informação coletada revela que todos os tipos de programas são utilizados, variando muito a intensidade. As escolas privilegiam os filmes alugados e os documentários, vindo em seguida a programação da TV Escola.

Quanto às disciplinas do currículo, os dados de 1998 mostram que ciências é a mais beneficiada com a programação da TV Escola em mais de 3/4 das escolas. Em seguida, estão história e geografia e meio ambiente. Já em relação às séries, verifica-se uma distribuição eqüitativa entre os dois grupos, de $1^{\mathrm{a}}$ à $4^{\mathrm{a}}$ e o de $5^{\mathrm{a}}$ à $8^{\mathrm{a}}$.

Indicadores de eficiência social: graus de satisfação dos usuários

O sistema educacional brasileiro é marcado fundamentalmente pelo processo tradicional de ensino, baseado apenas na atuação do professor, considerado o agente central e quase exclusivo de transmissão do conhecimento. Por isso mesmo, era de se supor que o desenvolvimento dos meios de comunicação e sua introdução no ensino provocassem fortes resistências mas também uma diferenciação de opiniões e adesões, segundo o papel e a função dos agentes considerados. Vejamos os resultados.

De maneira geral, os diretores apresentaram-se mais favoráveis à utilização da televisão e vídeo, independentemente da função à que se destina (capacitação docente ou trabalho com alunos). Desde seu primeiro ano de funcionamento, com efeito, o programa foi positivamente avaliado pelos diretores escolares e essa satisfação cresceu razoavelmente entre 1997 e 1998. Diretores de três, entre cada quatro escolas, avaliaram positivamente o conteúdo dos programas e sua eficiência para capacitar professores, enquanto aproximadamente 2/3 aprovaram também sua adequação ao currículo escolar (Quadro 5).

\section{QUADRO 5}

TV ESCOLA: AVALIAÇÃO DOS DIRETORES Brasil 1997-1998

Percentual de escolas urbanas

\begin{tabular}{|l|c|c|c|}
\hline \multicolumn{1}{|c|}{ Dimensões Avaliadas } & $\mathbf{1 9 9 7}$ & $\mathbf{1 9 9 8}$ & $\boldsymbol{\Delta}$ \\
\hline Adequação ao Conteúdo & 73 & 77 & 6 \\
\hline Adequação ao Currículo & 60 & 65 & 8 \\
\hline $\begin{array}{l}\text { Eficiência na Capacitação } \\
\text { dos Professores }\end{array}$ & 64 & 69 & 7 \\
\hline
\end{tabular}

Fonte: NEPP/UNICAMP, 1998

" = Taxa de crescimento 
Portanto, do ponto de vista da disposição desse agente educacional, o programa contava, em 1997 e 1998, com condições bastante positivas de implementação, disposição que se acentuou entre um ano e outro.

Também a opinião dos alunos ${ }^{14}$ sobre o uso da programação da TV Escola é positiva. Solicitados a avaliá-la, com notas, 58\% atribuíram-lhe notas altas (entre oito e dez), enquanto $24 \%$ manifestaram-se contrariamente, atribuindo-lhe notas baixas. É interessante notar, ainda, que a satisfação dos alunos aumenta à medida em que aumenta o número de vezes que viram os programas, ou à medida em que se intensifica a periodicidade com que suas escolas "passam" os filmes. Ou seja, opera aqui a lógica do "quanto mais vêem mais gostam", o que sugere forte potencialidade do programa.

\section{PRINCIPAIS DIFICULDADES E OBSTÁCULOS À IMPLEMENTAÇÃO DO PROGRAMA}

A pesquisa permitiu discriminar condicionantes do desempenho do programa, ou seja, identificar os fatores "externos" ao programa, mas presentes nas escolas, que pareciam condicionar os resultados encontrados. Para efeitos de análise, tais fatores foram agrupados em operacionais e institucionais, de um lado, e estruturais, de outro.

\section{Fatores operacionais e institucionais}

Para implementar o programa, as escolas se defrontaram com falta de funcionários e falta de tempo para realizar as tarefas de gravação, além de problemas técnicos nos aparelhos e desconhecimento dos procedimentos para operar os equipamentos, conforme os dados apresentados no Quadro 6.

QUADRO 6

TV ESCOLA. PRINCIPAIS DIFICULDADES ENFRENTADAS PELO PROGRAMA, SEGUNDO OS DIRETORES

Brasil 1997/1998

Percentual de escolas urbanas

\begin{tabular}{|l|c|c|c|}
\hline \multicolumn{1}{|c|}{ Dificuldades } & $\mathbf{1 9 9 7}$ & $\mathbf{1 9 9 8}$ & $\boldsymbol{\Delta}$ \\
\hline Falta de funcionários & 55 & 48 & -13 \\
\hline Falta de Tempo & 37 & 35 & -7 \\
\hline Problemas Técnicos & 28 & 35 & -5 \\
\hline Não sabem gravar & 18 & 9 & -48 \\
\hline
\end{tabular}

Fonte: NEPP/UNICAMP, 1998

. $=$ Taxa de crescimento

14. Os questionários foram respondidos apenas por diretores. Entretanto, na pesquisa de campo, Módulo II, realizada em 1997, a opinião dos alunos foi consultada por questionário aplicado a uma amostra não-aleatória de 
Entretanto, as quedas de participação desses fatores sugerem estar ocorrendo aprendizagem instituciona/ ${ }^{15}$ a respeito do programa. É interessante notar que a falta de funcionário exclusivo para gravar programas, apontada nos dois anos como principal fator, provavelmente reflete falta de pessoal em geral e a dificuldade da escola em redefinir internamente as funções, já que as tarefas de gravação dificilmente justificariam tal exclusividade.

Sabe-se que uma das principais dificuldades enfrentadas na implantação de inovações nas escolas é a inexistência de pessoal qualificado para realizar as novas e diferentes atividades. Dessa forma, capacitação e treinamento de funcionários ganham especial importância na determinação do sucesso ou do fracasso da implementação. No caso da TV Escola, a pesquisa mostrou que, em 1997, em todo o país, houve capacitação para a utilização pedagógica dos filmes em apenas $23 \%$ das escolas urbanas que receberam e instalaram o equipamento.

A instalação do Kit Tecnológico exige das escolas alguns requisitos, tais como uma sala adequada para colocar os aparelhos de televisão e videocassete e um lugar seguro para instalação da antena parabólica. Segundo os dados coletados, em 1997, apenas 27\% das escolas contavam com uma dependência exclusiva para o seu uso e 25\%, em 1998. A grande maioria instalou os equipamentos em dependências da escola utilizadas também para outros fins, tais como sala de professor, auditório, sala de aula etc. As demais escolas (cerca de 9\%, em 1997, e 8\%, em 1998) informaram que utilizaram um suporte móvel, que possibilita o deslocamento dos aparelhos de televisão e de vídeo para as diversas dependências da escola

A organização e distribuição do tempo de trabalho do professorobviamente afeta um programa que, afinal, depende do seu tempo para ser visto, assistido - além de reproduzido. Tratou-se então de verificar em que momento os docentes viam os filmes. Em pouco menos da metade das escolas (4l\%), assistiam aos filmes durante horário específico para reunião de professores. ${ }^{16} \mathrm{~A}$ inexistência de um horário na jornada do professor fora de sala de aula para assistir aos filmes foi mesmo apontada como um dos obstáculos enfrentados pelas escolas, coerentemente ao fato de que menos da metade oferecia condições mais propícias para a capacitação docente em serviço e no próprio local de trabalho. Entre as escolas que não utilizavam a programação para a capacitação docente, ${ }^{17}$ a inexistência de um horário específico na jornada do professor foi citada em primeiro lugar, entre os motivos que explicariam, segundo o diretor, o não uso dos filmes.

1559 alunos de $4^{\mathrm{a}} \mathrm{s}$ séries, em 66 escolas (estaduais e municipais) nos estados do Pará, Maranhão, Alagoas, Bahia, Espírito Santo, Minas Gerais, Goiás e Rio Grande do Sul. 80\% deles afirmaram gostar do uso de televisão em aula, mas apenas 58,4\% consideraram bom o funcionamento da TV Escola nas suas escolas.

15. Uma explicação mais detalhada sobre esse conceito será apresentada mais adiante.

16. Cabe lembrar que 17\% das escolas informaram que os professores não assistem aos filmes.

17. $37 \%$ do total de escolas que gravam. 
Mas os dados mostraram também que as escolas têm feito arranjos para superar esse obstáculo: é surpreendente, por exemplo, que 35\% das escolas informem que os professores assistiam aos filmes fora do horário das aulas e fora da escola. Em 25\% das escolas, fora do horário das aulas, embora na própria escola e em 20\%, durante o intervalo das aulas.

Outros fatores foram também assinalados pelo diretor, como responsáveis pelo modesto uso do programa. ${ }^{18}$ Como principal razão para explicar a não utilização em atividades pedagógicas com os alunos, $21 \%$ declararam "outro motivo", 16\%, o fato de a videoteca não estar organizada e 10\%, o hábito dos professores de utilizar apenas o livro didático, juntamente com o fato de a videoteca estar desorganizada.

Fatores estruturais e outras variáveis

Características estruturais da escola, por hipótese, condicionam o desempenho dos programas, em especial, de programas que contêm tão alta dose de inovação, como é o caso da TV Escola.

Se tomarmos algumas variáveis independentes e intervenientes - aqui qualificadas com uma certa liberdade como fatores estruturais - é de se notar a forte associação entre desempenho insuficiente do programa e determinadas caraterísticas das escolas, tais como o fato de serem municipais ou estaduais; seu porte e porte do município onde se localizam; caraterísticas de sua infra-estrutura; escolaridade e experiência do diretor; organização interna (possuir, por exemplo, uma associação de pais e mestres cumprindo funções de unidade executora de recursos) etc.

De modo a estimar o peso relativo desses fatores no desempenho do Programa TV Escola, foi aplicado aos dados de 1997 e 1998 um modelo de regressão logística, ${ }^{19}$ que indica as probabilidades (ou chances) de associação entre aquelas variáveis e os indicadores de desempenho do programa. Veja-se nas figuras abaixo as principais relações encontradas.

Chama a atenção, em primeiro lugar, a heterogeneidade entre as escolas estaduais e municipais. Nessas últimas, tal como indicam as associações, imperam condições desfavoráveis ao bom desempenho do programa. Mesmo em municípios nos quais coexistem os dois tipos de escolas, são as escolas municipais as que tendem, probabilisticamente, a apresentar as piores oportunidades de bom desempenho: é maior a probabilidade, em comparação às estaduais, de não terem implantando o programa, de não gravarem os filmes e, quando o fazem, de não utilizarem esses filmes tanto na capacitação dos professores quanto nas atividades com alunos.

18. Foram apresentadas as seguintes alternativas: o conteúdo dos programas não é adequado às necessidades da escola; os professores não têm interesse; não há um horário específico na jornada do professor; outro motivo.

19. Trabalho elaborado pela estatística Stella M. B. da Silva Telles, no âmbito da pesquisa realizada pelo NEPP. 


\title{
TV ESCOLA
}

\section{Condicionantes estruturais do desempenho}

\author{
Levantamento 1997 \\ Levantamento 1998 \\ Escola municipal $X$ escola estadual
}

4, 9 vezes mais chances de não ter o Programa instalado

2,3 vezes mais chances de não gravar os programas

1,5 vez mais chance de pouco uso dos equipamentos com capacitação docente (No $\mathrm{SE} 2,6$ vezes mais)

1,5 vez mais de chance de pouco uso dos equipamentos com atividades pedagógicas (No $\mathrm{SE} 3,8$ vezes mais)
3, 8 vezes mais chances de não ter o Programa instalado 1,8 vez mais chance de não gravar os programas

1, 3 vez mais chance a mais de pouco uso dos equipamentos com capacitação docente (No SE 2,5 vezes mais) 1, 6 vez mais chance de pouco uso dos equipamentos com atividades pedagógicas (No SE 3,5 vezes mais)

\section{Escola média $X$ escola grande}

1,4 vez mais chance de não gravar

2,6 vezes mais chances de adquirir equipamentos através da Secretaria Estadual ou Municipal de Ensino (No Sul 2,9 vezes mais de adquirir através das próprias escolas)

1, 6 vez mais chance de não ter o programa instalado 1, 9 vez mais chance de não gravar

2,1 vezes mais chances de adquirir equipamentos através da Secretaria Estadual ou Municipal de Ensino

\section{Escola pequena $X$ escola grande}

4,3 vezes mais chances de não ter o programa instalado

2,3 vezes mais chances de não gravar

1,9 vez mais chance de adquirir equipamentos através da Secretaria Estadual ou Municipal de Ensino na região $\mathrm{SE} 5,9$ vezes de adquirir equipamentos através das própria escola na região Sul, 3,8 no C. @este, e 2,4 vezes no Norte e Nordeste

1,8 vez mais chance dos diretores terem declarado enfrentar dificuldades
3,8 vezes mais chances de não ter o programa instalado

3,2 vezes mais chances de não gravar

1,5 vez mais chance de adquirir equipamentos através da Secretaria Estadual ou Municipal de Ensino na região SE 2,5 vezes mais de adquirir equipamentos através das própria escola na região C. Oeste; 5,6 vezes mais na região Norte e 1, 9 vezes mais no Nordeste 1,6 vez mais chance dos diretores terem declarado enfrentar dificuldades

\section{Escola de município médio ou pequeno $X$ escola de município grande}

de 1,3 a 1,8 vez mais chance de não ter o programa nas regiões Norte, Nordeste e Centro-Oeste. As regiões $\mathrm{SE}$ e SU tem 2 vezes mais chances de ter o programa. (Escolas de municípios pequenos da região SE têm 6, 3 vezes mais de ter o programa)

1, 3 vez mais chance de realizar as gravações dos programas nas escolas dos municípios médios e 2 vezes mais nos pequenos

1,4 vez mais chance do uso dos equipamentos para capacitação dos professores ser freqüente nas escolas dos municípios médios e 1,9 nas escolas dos municípios pequenos

1,4 vez mais chance do uso dos equipamentos para atividades pedagógicas ser freqüente nas escolas dos municípios médios e 2 vezes mais nas escolas dos municípios pequenos de 1,2 a 1, 7 mais chance de ter o programa nas regiões Norte, Nordeste e Centro-Oeste. As regiões SE e SU têm chances entre 1,4 e 1,9 a mais de ter o programa. (Escolas de municípios pequenos da região SE tem 7,7 vezes mais chances de ter o programa)

1,2 vez mais chance de realizar as gravações dos programas nas escolas dos municípios médios e 1,5 nos pequenos 1,2 vez mais chance do uso dos equipamentos para capacitação dos professores ser freqüente nas escolas dos municípios médios e 1,5 nas escolas dos municípios pequenos

1, 7 vez mais chance do uso dos equipamentos para atividades pedagógicas ser freqüente nas escolas dos municípios médios e 1,6 nas escolas dos municípios pequenos

\section{Condicionantes institucionais do desempenho Levantamento 1997 Levantamento 1998 \\ Escola com experiência anterior em gestão de recursos $X$ escolas sem experiência}

5 vezes mais chances de ter o programa implantado (No SE 7 vezes mais e no NO 2,8)

2,5 vezes mais chances de gravar os programas

5,6 vezes mais chances de adquirir equipamentos através da própria escola

1, 1 vez mais chance da escola ter enfrentado problemas 1, 6 vez mais chance do uso dos equipamentos para capacitação dos professores ser freqüente (No SE 4 vezes mais chances de uso freqüente e no Sul 1,7 de chance a mais do uso ser pouco freqüente)

1, 5 vez mais chance do uso dos equipamentos para atividades pedagógicas ser freqüente (No SE e no NO mais de 2,7 vezes mais chances)
4 vezes mais chances de ter o programa implantado (No CO, NE e SE cerca de 3 vezes mais e no Sul 13 vezes mais)

3,3 vezes mais chances de gravar os programas

4, 5 vezes mais chances de adquirir equipamentos através da própria escola

$32 \%$ a menos de chance da escola ter enfrentado problemas

$79 \%$ de chance a mais de chance do uso dos equipamentos para capacitação dos professores ser freqüente (No SE 3,4 vezes mais chances de uso freqüente) 2,5 vezes mais chances do uso dos equipamentos para atividades pedagógicas ser freqüente (No NO e CO 3 vezes mais, SE 2 vezes, no Sul 9 vezes mais) 


\section{Escolas com unidades executoras $X$ escolas que não as possuem}

3,8 vezes mais chances de ter o programa implantado (No SE 9,5 vezes mais e no NO e NO 2)

2,3 vezes mais chances de gravar os programas (SE 4,7 vezes mais e no $\mathrm{NE} 28 \%$ de chances a menos de gravar) 3 vezes mais chances de adquirir equipamentos através da própria escola (SE 9,8 vezes mais e $\mathrm{NE} 1,4$ de chance a menos)

1,7 vez mais chance da escola não ter enfrentado problemas 1,2 vez mais chance do uso dos equipamentos para capacitação dos professores ser freqüente (No SE 2,8 vezes mais chances de uso freqüente e no sul 2 vezes mais chances do uso ser pouco freqüente)

1,7 vez mais chance do uso dos equipamentos para atividades pedagógicas ser freqüente (No SE 3,6 vezes mais chances e no Sul 1,2 menos)
5 vezes mais chances de ter o programa implantado (No $\mathrm{SE} 3$ vezes mais e no NE 1,5 )

2,3 vezes mais chances de gravar os programas (NE 1,9 vez mais e no Sul 5,3)

2,5 vezes mais chances de adquirir equipamentos através da própria escola (NE 4,5)

3,7 vezes mais chances da escola não ter enfrentado problemas

1, 3 vez mais chance do uso dos equipamentos para capacitação dos professores ser freqüente (No CO e Sul 1,4 de chance a menos)

1, 3 vez mais chance do uso dos equipamentos para atividades pedagógicas ser freqüente (No SE 1,2 de chance a menos)

\section{Escolas que têm projeto pedagógico $X$ escolas que não têm}

2,4 vezes mais chances de ter o programa implantado 1, 3 vez mais chance da escola adquirir equipamentos através delas mesmas do que pelas Secretarias de Educação

2,4 vezes mais chances de realizar gravações

1,3 vez mais chance de ter declarado que não enfrentou dificuldades

por volta de 2 vezes mais chances da periodicidade de uso dos equipamentos com capacitação docente e atividades pedagógicas ser freqüente
2,1 vezes mais chances de ter o programa implantado 1,6 vez mais chance da escola adquirir equipamentos através delas mesmas do que pelas Secretarias de Educação

3,1 vezes mais chances de realizar gravações

1,1 vez mais chance de ter declarado que não enfrentou dificuldades

1,6 vez mais chance da periodicidade de uso dos equipamentos com capacitação docente ser freqüente e 1, 3 de chance a mais do uso com atividades pedagógicas ser freqüente

\section{Escolas que têm coordenador pedagógico $X$ escolas que não têm}

3 vez mais chance de ter o programa implantado (No Norte e no C. Oeste mais de 2,3)

1,2 vez menos chance da periodicidade de uso dos equipamentos em capacitação docente ser freqüente 1,1 vez mais chance da periodicidade de uso dos equipamentos em atividades pedagógicas ser freqüente
4,8 vezes mais chances de ter o programa implantado (No Norte 7,5 vezes e no Nordeste 4 vezes)

1, 5 vez mais chance da periodicidade de uso dos equipamentos em capacitação docente ser freqüente

1, 8 vez mais chance da periodicidade de uso dos equipamentos em atividades pedagógicas ser freqüente

\section{Desempenho segundo o perfil do diretor}

Levantamento 1997

Levantamento 1998

\section{Diretores com $1^{\circ}$ ou $2^{\circ}$ grau $X$ Diretores com curso superior}

têm até 2 vezes mais chances de não implementar o programa ( diretores com $1^{\circ}$ grau: 9,6 vezes mais chances de não implementar no Norte e 16,7 na região C.Oeste 2 vezes mais chances de não realizar gravações dos programas

diretores com o $1^{\circ}$ grau têm 2 vezes mais chances de fazer uso freqüente dos equipamentos para capacitação de professores têm até 2 vezes mais chances de não implementar o programa diretores com $1^{\circ}$ grau: 3 vezes mais chances de não implementar na região C.Oeste

têm entre 1, 6 a 1,9 vez mais chance de não realizar gravações dos programas

diretores com $\circ 1^{\circ}$ grau têm 1,5 vez mais chance de fazer uso periódico dos equipamentos com capacitação docente e 1, 3 a mais de chance do uso ser periódico com atividades pedagógicas

\section{Diretores com treinamento específico $\times$ Diretores que não o tiveram}

2,6 vezes mais chances de implementar o programa (4,3 no NE e 3, 9 no CO)

1,2 vez mais chance de gravar os programas

1,5 vez mais chance de adquirir os equipamentos através da própria escola do que através das secretarias de educação (No NE 2,8 vezes mais chances)
1,7 vez mais chance de implementar o programa $(2,2$ no NO e 1,9 no NE)

1,2 vez mais chance de gravar os programas

2 vezes mais chances de adquirir os equipamentos através da própria escola do que através das secretarias de educação

Pode-se aventar, como explicação para tais diferenças, as más condições de infraestrutura e a precária organização dos sistemas municipais em todo o país. É também possível que tenha havido menor envolvimento dessas instâncias administrativas no apoio às 
unidades escolares para a implementação do programa. Cabe ressaltar, no entanto, que os diferenciais desses condicionantes reduziram-se significativamente de 1997 para 1998, o que sugere melhora nas condições gerais das escolas municipais e um maior envolvimento institucional das prefeituras e secretarias municipais de educação no funcionamento da TV Escola.

O porte da escola mostra-se também um fator importante de discriminação dos resultados e probabilidades. Assim, as escolas pequenas revelam maiores riscos de enfrentarem dificuldades para implantar o programa (inexistência de sala exclusiva para instalar o equipamento e de coordenador para operar os equipamentos etc.), quando comparadas às médias e grandes.

É interessante notar, ainda, a forte associação entre condições institucionais positivas das escolas - possuir coordenador pedagógico, ter elaborado projeto pedagógico, ter tido experiência anterior em gestão de recursos - e melhores probabilidades de, também, terem implementado melhor o Programa TV Escola: as chances de que isso aconteça variam entre duas e quatro vezes, mas em algumas regiões, chega a nove vezes mais!

Finalmente, é notável a influência da escolaridade e treinamento do diretor nas chances de melhor ou pior desempenho do programa. De fato, como se verifica pelo último bloco de relações, chegam a duplicar as probabilidades de uma escola não implantar o programa, se seu diretor tem apenas o $1^{\circ}$ ou o $2^{\circ}$ grau, quando comparada à escola em que o diretor tem curso superior. Também as escolas cujo diretor teve treinamento específico para esta função gerencial têm maior probabilidade de implementar o Programa TV Escola, em comparação àquelas cujos diretores não possuem tal perfil.

\section{À GUISA DE CONCLUSÃO: ÊXITOS E OBSTÁCULOS DA IMPLEMENTAÇÃO DO PROGRAMA TV ESCOLA}

Mais que uma conclusão, o que aqui nos anima é a possibilidade de enfatizar, no estudo da implementação do Programa TV Escola, algumas dimensões que nos pareceram cruciais - se assim se pode dizer - tanto para explicar seus êxitos quanto para entender a natureza dos obstáculos que enfrenta.

\section{A dimensão temporal}

Processos de implementação desenvolvem-se no tempo. Ou seja, a verificação de fatores condicionantes de êxitos e fracassos somente ganha sentido se referida aos tempos específicos do processo. Essa observação vale especialmente para os estudos e avaliações de processo de implementação de programas que visam introduzir inovações no interior da escola pública, como é o caso dos programas avaliados neste trabalho.

O movimento do primeiro ciclo examinado - entre 1996 e 1997 - oferece boa oportunidade para se verificar a dimensão temporal do processo e o comportamento dife- 
renciado das variáveis entre um período e outro. Assim, entre o segundo semestre de 1995 mas principalmente ao longo de 1996, o Programa de Apoio Tecnológico realizou-se quase que completamente: não apenas o MEC transferiu para os organismos estaduais e municipais os recursos totais destinados ao programa como, na grande maioria dos estados e municípios, as aquisições dos cerca de 45 mil kits e a sua distribuição para as unidades escolares foram completadas.

Diferenças de ritmo e de condições de implementação caracterizaram a etapa imediatamente seguinte do programa, qual seja, a da instalação e início de operações das antenas parabólicas nas escolas. $\bigcirc$ processo não apenas foi mais demorado como teve de haver-se com diversos grupos de agentes, em especial as empresas vencedoras das licitações — foram várias, em todo o país - e que operaram rotinas, ritmos e mecanismos distintos para instalar e colocar em operação o novo equipamento. Ocorreu uma certa defasagem entre o início do Programa TV Escola — março de 1996 - e a completa instalação das antenas, que se prolongou até o segundo semestre daquele ano. Sensíveis a estas diferenças temporais, os indicadores de cobertura registram diferenças entre escolas que possuíam o equipamento e escolas em que estes já se encontravam instalados.

Na verificação dos resultados, a periodização do Programa TV Escola também deve ser considerada. Embora anunciado no segundo semestre de 1995, somente teve início, de forma regular, em março de 1996. Portanto, nossos dados de 1997 referem-se a um tempo em que o programa completava pouco mais de um ano de vida — período tipicamente de implementação e regularização das suas dinâmicas e rotinas. Ora, os resultados encontrados retratam tipicamente uma etapa inicial do processo, em que não estavam ainda dados e amadurecidos todos os supostos institucionais e dinâmicos do programa. Diferentemente, os dados correspondentes a 1998 retratam uma situação em que, embora o programa viva ainda sua juventude, pôde já instalar todos seus mecanismos dinâmicos, entre eles a capacitação e a rotinização da distribuição do material, etc.

Por outro lado, como se sabe, as "instituições aprendem". No caso que nos interessa, a aprendizagem institucional refere-se tanto aos agentes implementadores diretos do TV Escola - desde sua coordenação nacional até os professores e alunos - quanto às organizações em que opera (as secretarias estaduais e municipais de educação). Logo, em grande medida, os indicadores correspondentes a 1998 devem ter captado as melhoras de desempenho advindas destas aprendizagens e acumulação de experiências.

A maior inovação proposta pelo Programa TV Escola, no entanto, diz respeito à utilização da educação a distância na capacitação de professores e a introdução de novas tecnologias educacionais nas escolas públicas. A capacitação de professores em serviço constitui, sem dúvida, um dos pré-requisitos fundamentais para a melhoria da qualidade do ensino e para a introdução de inovações educacionais na rede de ensino. Mas, se por um lado, alguns estudos apontam para a importância da capacitação, considerada como uma variável que tem um impacto diferencial sobre o rendimento de aprendizagem dos alunos, por outro, sabe-se também da imensa dificuldade em realizar cursos de capacitação eficientes e que 
atinjam a grande maioria dos profissionais, principalmente num país com as dimensões e a heterogeneidade do Brasil.

Nesse contexto, o MEC, ao implantar os Programas Apoio Tecnológico e TV Escola, estabelecendo como meta a distribuição de televisão, vídeo e antena parabólica e transmissão diária de uma programação educativa, propiciou a todas as escolas públicas condições de acesso a esses novos meios para melhorar a qualidade do ensino. Como se demonstrou, a quase totalidade das escolas públicas com mais de cem alunos conta com o kit tecnológico. No entanto, a gravação de filmes e a sua plena utilização na capacitação docente ainda não ocorrem satisfatoriamente. De qualquer maneira, atualmente, estima-se que quase um miIhão de professores lecionam em escolas que possuem o kit, mais de 500 mil encontram-se em escolas que gravam filmes, cerca de 25 milhões de alunos freqüentam escolas que possuem equipamento de TV e vídeo e aproximadamente 18 milhões deles estão em escolas que gravam filmes. São inegáveis, nesse sentido, as potencialidades do programa.

\section{A descentralização e as coalizões de apoio}

Os Programas de Apoio Tecnológico e da TV Escola oferecem também uma interessante oportunidade para que se reflita sobre inovações e estratégias de descentralização de programas federais em estruturas federativas como a do Brasil. Vejamos.

Ao optar pela estratégia de descentralização radical, repassando o recurso financeiro para os estados e municípios adquirirem os equipamentos para suas redes de ensino, o MEC introduziu uma inovação na compra e distribuição de bens. Possivelmente, essa opção possibilitou os níveis de cobertura alcançados, entregando a aproximadamente $78 \%$ das escolas urbanas com mais de cem alunos, num período curto de tempo, o kit tecnológico.

A implementação do PAT deu-se de modo relativamente ágil, se se considerar as tradicionais demoras que ocorrem em programas sociais que envolvem sistemas de compras e distribuição de bens. $\bigcirc$ modelo básico de descentralização sobre o qual repousou a transferência dos recursos federais para os estados federados, descentralizando radicalmente o processo de aquisição, foi reconhecido pela maior parte dos agentes implementadores e beneficiários como bastante eficaz. Como se sabe, os processos de aquisição de bens e serviços, sobretudo pelas dificuldades das licitações e as referentes aos sistemas de distribuição, constituem, ainda hoje, uma das grandes dificuldades enfrentadas por programas públicos, particularmente se realizadas de modo centralizado e pelo governo federal. Desse modelo quis se afastar o PAT. A pulverização de ações de compra, a complexidade dos processos de distribuição de bens por todo o país, enfim, as enormes exigências de engenharia e logística para entregar aparelhos eletrodomésticos e pretender instalar antenas parabólicas em mais de quarenta mil unidades escolares distribuídas por todo o território nacional, além de desafiante não deixou de significar também uma das mais fortes inovações institucionais em um país secularmente marcado pela centralização. Por isso mesmo, para além dos seus impactos 
sobre os comportamentos educacionais, a experiência recente do PAT traz consigo lições importantes em matéria de descentralização de programas sociais. ${ }^{20}$

O Programa TV Escola reforça, em tese, a autonomia da escola, mas a pesquisa mostrou que o seu desempenho depende decisivamente da atuação das secretarias estaduais e prefeituras. Assim, é fundamental identificar as diferentes formas de inserção institucional do programa nas estruturas organizacionais dos estados e municípios. ${ }^{21}$ De maneira geral, as secretarias estaduais de educação contam, na sua estrutura organizacional, com um órgão ou pelo menos um técnico responsável, exclusivamente destinado a acompanhar o programa. Muitas envolveram também suas instâncias regionais, descentralizadas, que desempenham papel importante no desenvolvimento e acompanhamento do programa. Em alguns estados, essas instâncias demonstraram ser bastante fortes e operantes, tendo a Secretaria de Educação do Estado a preocupação de equipá-las com o kit, para poderem gravar e implementar o programa e, assim, auxiliarem as escolas com empréstimos. Em outros, o setor mostrou-se precário, com poucos técnicos, e nem sempre capacitados, trabalhando em local inadequado para realizar as tarefas que o programa exige. As secretarias reivindicavam ao MEC a instalação de um kit nas delegacias e o recebimento do material impresso para poderem desenvolver suas atividades.

Pôde-se verificar, entretanto, que as secretarias estaduais têm envidado esforço para implementar o programa, realizando diversas atividades, tais como: gravação, catalogação e organização de videoteca para empréstimos às escolas e demais interessados; manutenção de serviços de empréstimos e de reprodução de fitas; fortalecimento e envolvimento dos seus órgãos regionais com os municípios para o trabalho com as escolas; promoção de grandes encontros de sensibilização e capacitação dos agentes; manutenção de calendário anual de oficinas pedagógicas para agentes escolares; reuniões periódicas com os coordenadores pedagógicos; manutenção de equipe interdisciplinar para estudos de formas para o uso do programa e para capacitação de professores.

20. As informações regionais mostram grandes diferenças, principalmente no que tange às dificuldades para realizar as licitações: muitas prefeituras e mesmo estados enfrentaram atrasos e alguns precisaram refazer todo o processo devido a inúmeras irregularidades cometidas. No entanto, há os casos bem-sucedidos de alguns estados (Minas Gerais e Bahia, por exemplo) que repassaram o recurso financeiro para as próprias unidades escolares comprarem o kit. Também as escolas da rede estadual de São Paulo receberam os recursos financeiros para adquirir os equipamentos, de acordo com as informações obtidas no módulo qualitativo Il da pesquisa, realizado em dez escolas em São Paulo. De acordo com os depoimentos, esse procedimento foi avaliado positivamente e parece não ter ocorrido nenhum problema nem com a compra nem com a qualidade dos equipamentos.

21. Há que se considerar também as Delegacias Regionais do MEC - DEMECs - que tinham como função divulgar - PAT/TV Escola, realizando reuniões com os municípios, principalmente, para acompanhar o Programa em seus aspectos operacionais e pedagógicos, para organizar e ou participar junto com as secretarias de educação, de treinamentos de capacitação dos agentes envolvidos com o programa e manter o MEC informado sobre a sua implantação nas diferentes regiões. Neste sentido, a maioria das DEMECs coordenava, à época da pesquisa em campo, a aplicação de instrumental, com objetivo de levantar informações sobre o funcionamento do programa no Estado. O nível de envolvimento das DEMECs variou bastante, entre aquelas de muita iniciativa e outras, que se mantiveram à margem, revelando pouco conhecimento sobre o programa. 
Quanto aos municípios, a maioria deles não tinha em sua estrutura organizacional um técnico responsável pela TV Escola. Em todos os 34 municípios estudados, foram identificados treze técnicos, dos quais apenas seis respondiam de fato pela função e possuíam informações sobre a TV Escola. Por sua vez, somente três prefeituras estruturaram setores administrativos específicos para coordenar e supervisionar a implementação do programa. Ressaltase o caso do município de Santarém, que ofereceu um apoio efetivo na implementação da TV Escola, criando na prefeitura a função de orientador de vídeo, ao mesmo tempo em que designou um profissional para cada escola municipal, com treinamento específico para a função, coordenado pelo referido orientador.

A radical descentralização levou a uma inserção muito frágil do programa nas redes, já que não houve previamente acertos e articulações bem estabelecidas com as secretarias estaduais e municipais de educação, de tal modo que seus papéis e funções, na TV Escola, estivessem bem definidos. Ora, a conseqüência foi que as escolas, na rotina de implementação do programa, careceram de sistemas de apoio para a utilização dos equipamentos, ou de recursos financeiros para a sua manutenção ou, ainda, de recursos humanos para operacionalizá-lo.

Foram desconsideradas, dessa forma, diferentes dimensões e heterogeneidades das redes públicas de ensino; distintas capacidades administrativas e de gestão dos estados, dos municípios e das escolas. De fato, essa heterogeneidade estrutural e complexidade institucional do país podem atuar como fatores que facilitam ou criam obstáculos à implementação do programa. Assim é que as secretarias estaduais, na sua grande maioria, contam com uma estrutura organizacional de apoio ao programa. Muitas secretarias já possuíam experiência e uma certa tradição no uso do ensino a distância, sendo a TV Escola apenas mais um programa a ser incorporado ao conjunto de atividades. Para algumas secretarias estaduais e talvez para a maioria das prefeituras, a TV Escola passou a ser o primeiro contato com o ensino a distância e a primeira possibilidade de capacitação de professor em serviço. No entanto, o MEC estabeleceu um canal de contato apenas com as escolas, deixando marginalizadas as secretarias de educação, principalmente as municipais.

Se a opção de se dirigir diretamente à unidade escolar pode ser considerada positiva, porque possibilitou que o beneficiário tivesse acesso ao programa sem depender de complexos e lentos processos burocráticos, desconsiderou-se, no entanto, que a escola faz parte de uma organização institucional com hierarquias e rotinas. Entende-se, assim, o depoimento de inúmeros atores que concluem que o programa "está solto" ou "ninguém é responsável por ele". Os diretores não conseguem informações nas secretarias, principalmente dos municípios, porque os técnicos destas também pouco sabem sobre o programa.

Com relação aos municípios há que se considerar também o cenário com que o programa se defrontou em 1996 e, principalmente no ano de 1997, quando foram empossadas as novas gestões. Em 1996, muitos municípios estavam em condições inadimplentes e não puderam assinar o convênio. Já em 1997, as novas gestões municipais pouco conheciam sobre o programa. Como as prefeituras possuem pouca institucionalidade, 
em muitos lugares não foi encontrado nenhum documento sobre o programa. Essa mudança contribuiu para que este ficasse ainda mais "solto". Há, entretanto, casos positivos e isolados, como a prefeitura de Santarém, cujo secretário de educação, ao assumir em 1997, criou todas as condições necessárias para o funcionamento adequado do programa, inclusive contratando profissionais para coordenar as atividades da TV Escola.

Diante das circunstâncias que combinaram amplo escopo e alta intensidade da inovação, altos níveis de riscos e incertezas e preocupação difusa em criar bases de apoio ao processo de introdução de inovações, o MEC, já durante o ano de 1996, passou a buscar o apoio do conselho de Secretários Estaduais de Educação - Consed, estabelecendo uma relação mais próxima com as secretarias estaduais. Para tanto, foram realizados um sistema de acompanhamento da implementação e workshopspara discutir o desempenho do programa.

A ação dos agentes

De acordo com a literatura sobre o processo de implementação de inovações, o comportamento das ações está fortemente associado à presença e ação dos atores envolvidos nesse processo, em especial os chamados agentes de mudança. Entende-se por agentes de mudança

[...] grupos alocados especialmente em alguns bolsões ou organismos da burocracia capazes de influenciar as decisões iniciais, desencadear processos de mudanças e sustentá-los por período de tempo afetando, no momento posterior, o comportamento do conjunto dos agentes implementadores. (NEPP, 1996. p.43)

Sem dúvida, a implementação de inovações educacionais provoca alterações nos comportamentos dos agentes e das organizações, atitudes de resistência ou adesão. Contudo, se se considera que implementar inovações implica um processo e não eventos isolados, não basta identificar apenas as resistências e adesões, é preciso compreender a ação dos agentes durante um período de tempo e as possibilidades de mudanças pela criação de condições de trabalho sistemático nas novas direções propostas. É preciso compreender que a estratégia de implementação deve considerar o potencial de cada agente e o seu aperfeiçoamento permanente.

Nesse momento inicial da implementação, uma boa parte das escolas reagiu baseada em suas rotinas cristalizadas: "não temos recursos humanos para fazer o programa funcionar e o professor não tem tempo disponível em sua jornada para utilizá-lo." Ora, muitas escolas, apesar de possuírem um coordenador pedagógico, não gravam filmes, como os dados apontaram; assim como, em algumas escolas do estudo de caso, os professores conseguiram criar alternativas e superaram o obstáculo da inexistência de tempo. Os formuladores e os principais agentes implementadores precisam identificar essas alternativas, reforçá-las positivamente e criar condições para que as demais escolas vislumbrem a possibilidade de romper com a rotina e de incorporar a inovação em seu cotidiano. 
A necessidade de se criarem novas alternativas a essas ações que apresentam obstáculos durante o processo de implementação emerge da constatação do grau de satisfação do usuário que aponta para um quadro de boa aceitação do programa, manifesto na forte aprovação dos diretores: $73 \%$ dos diretores consideraram bom o conteúdo dos programas da TV Escola e 65\% deles aprovaram o uso da televisão na educação.

Também deve-se considerar a alta utilização dos programas da área de ciências. Essa constatação sugere que, possivelmente, as resistências iniciais estejam sendo ultrapassadas, uma vez que, possuindo o equipamento, a escola passa a utilizá-lo exatamente naquelas atividades e disciplinas em que o programa apresenta melhor desempenho ${ }^{23}$. Esses contatos iniciais, provavelmente, levarão os professores a um longo processo de descoberta das potencialidades desses recursos em todas as áreas do currículo.

\section{Considerações sobre a eqüidade}

Finalmente, o estudo permite algumas especulações sobre programas como o da TV Escola e a eqüidade. Indubitavelmente, o programa oferece às escolas aumento da possibilidade de capacitação do professor com qualidade em todas as regiões do país; além de possibilitar a alunos de todas as regiões e todas as redes de ensino acesso à TV e a informações qualitativas. Os dados da pesquisa apontam, entretanto, para uma situação na qual as escolas da região Nordeste, as escolas pequenas e as escolas dos municípios pequenos concentram as situações negativas - menos kit, mais equipamentos que não funcionam e menor número de gravações. Mas há também as escolas das regiões Sudeste e Sul, as escolas grandes e as escolas dos municípios médios que apresentam a melhor cobertura, mais equipamentos funcionando e mais escolas que gravam filmes. Entretanto, é preciso ressaltar que nas regiões e redes de ensino menos ricas e favorecidas, marcadas pela carência de material didático e inexistência de cursos de capacitação, a chegada da programação da TV Escola, possivelmente, deva causar um impacto maior.

A temática da introdução e implementação de inovações em políticas públicas já existentes vem ganhando centralidade na literatura, já que é nesse campo que freqüentemente as autoridades governamentais esbarram com dificuldades institucionais de monta, não apenas no que se refere à capacidade de as organizações suportarem com eficácia as novas formas, mas também - e principalmente - porque o comportamento de aceitação ou de adesão dos agentes que implementam os programas, que estão sendo mudados ou introduzidos torna-se crucial para seu êxito ou fracasso.

22. De fato, há evidências que demonstram que as crianças podem aprender bem pela televisão. Embora não existam muitos estudos nessa área, no Brasil, sem dúvida, a utilização da televisão e do vídeo possibilitam um enriquecimento do processo de ensino-aprendizagem, por exemplo, nas áreas de ciências e geografia, podendo se repetir várias vezes um experimento, ou mostrar situações que não são facilmente observáveis. 


\section{REFERÊNCIAS BIBLIOGRÁFICAS}

CHADWICK, C. B. Tecnología educacional para el docente. Barcelona: Paidós, 4. ed., 1997.

NEPP. Avaliação do processo de implementação do projeto "novações no ensino básico" e de algumas medidas da Escola-Padrão: relatório integrado. São Paulo: NEPP/UNICAMP/ Secretaria da Educação de São Paulo, 1996.

- Avaliação da Descentralização de Recursos do FNDE e da Merenda Escolar. síntese dos resultados. Campinas: NEPP/UNICAMP, 1997.

POPPOVIC, P. P. Educação a distância: problemas da incorporação de tecnologias educacionais modernas em países em desenvolvimento. Em Aberto, v. 16, n.70, p.5-8, 1996.

SARAIVA, T. Educação a distância no Brasil: lições da história. Em Aberto, v. 16, n.70, p. 17-27, 1996. 